\title{
Menopause among Yemen Women
}

\author{
Fawzia AbdulHalim1, Amat Alkhlig Mehras², Ali Assabri³, \\ Mohamed Alkobaty ${ }^{4}$, Saba'a Alawadi ${ }^{5}$, Ammar Albourhi 6
}

\author{
${ }^{1}$ Nursing Division, Faculty of Medicine, University of Sana'a, Sana'a, Yemen \\ ${ }^{2}$ Department of Obstetrics and Gynecology, Faculty of Medicine, Dhamar University, Dhamar, Yemen \\ ${ }^{3}$ Department of Community Medicine, Faculty of Medicine, University of Sana'a, Sana'a, Yemen \\ ${ }^{4}$ Department of Obstetrics and Gynecology, Faculty of Medicine, University of Sana'a, Sana'a, Yemen \\ ${ }^{5}$ Training and Research Centre, Al Thawra Hospital, Sana'a, Yemen \\ ${ }^{6}$ University of Science and Technology Hospital, Sana'a, Yemen \\ Email: ammaralbourhi@gmail.com
}

How to cite this paper: AbdulHalim, F., Mehras, A.A., Assabri, A., Alkobaty, M., Alawadi, S. and Albourhi, A. (2018) Menopause among Yemen Women. Advances in Aging Research, 7, 65-77.

https://doi.org/10.4236/aar.2018.74006

Received: November 19, 2017

Accepted: July 7, 2018

Published: July 10, 2018

Copyright $\odot 2018$ by authors and Scientific Research Publishing Inc. This work is licensed under the Creative Commons Attribution International License (CC BY 4.0).

http://creativecommons.org/licenses/by/4.0/

\begin{abstract}
Introduction: Age at menopause, influencing factors associated, symptoms related and protective health behavior vary among populations. Objectives: Objectives of the study were to estimate the age at menopause, identify associated factors, assess the prevalence of menopausal symptoms and relate protective health behavior among Yemeni women. Methodology: A retrospective cross-sectional study was conducted on 1000 women naturally menopause aged 40 - 60 recruited from women community Centres in Sana'a city. Results: The mean age at menopause was found to be $47.8 \pm 1.2$ years. Significant influencing factors were genetic, biological, physical characteristics, weight, height, BMI, and physiological characteristic, such as menarche age, reproductive history, parity and abortion. Socioeconomic status had no significant influence. Most prevalent menopausal symptoms were hot flushes and sleep problems. The great majority of the women did not practice any special protective health behavior. Conclusion: Further studies on menopause phenomena are needed. Protective health behavior education efforts are made to increase women knowledge about menopause and promote menopausal women quality of life.
\end{abstract}

\section{Keywords}

Menopausal Age, Influencing Factors, Menopausal Symptoms,

Protective Health Behaviors, Yemeni Women

\section{Introduction}

Menopause is a milestone in the woman's life. It marks the cessation of the repro- 
ductive capacity. Natural menopause occurs after 12 consecutive months of amenorrhea with no obvious pathological reason [1]; it usually occurs at the 50th year. The mean life expectancy for women worldwide has raised from 50 to 81.7 [2].

The number of menopausal women in the world is expected to rise from of a total of 467 million to a total of 1200 million. By the year 2030, 76\% of the projected number is likely to be in the developing counties [3]. Menopause elicits a variety of symptoms that affect each woman in different ways from the slight discomfort to the worse. Menopause decreases women quality of life and declines their health status [4]. The most common symptoms associated with menopause are hot flushes [5], genitourinary problems [6] [7], sexual problems [8], mood changes [9], heart [10] and bone [11] problems.

The age of natural menopause generally clusters around 44 and 55 years of age, for women worldwide [5]. The average age at menopause in developed countries is about 51 years [1]. The data about age at menopause in developing countries are inconsistent. However, the age tends to be lower as it ranges between 43 to 49 years [3].

Menopause increases the risk for the development of medical conditions e.g. cardiovascular diseases, osteoporosis, and cancer. Mortality implication of menopause is considerable [12]. Menopausal age is an important indicator of subsequent morbidity and mortality in women. Early age at menopause increases the risk of cardiovascular diseases [13], osteoporosis [14], colorectal cancer [15], and decline of cognitive ability [16]. Late age of menopause may increase the risk of endometrial [17], ovarian [18] and breast cancer [19].

There are various factors, which are believed to influence a woman's age at menopause, like, socio-demographic and biological factors [20] [21].

The connection between menopausal age and risk factors of medical conditions makes age at menopause an important epidemiological issue.

This study was done to estimate the age of natural menopause in Yemeni women, to identify the various factors influencing it and to assess the prevalence of menopausal symptoms and menopausal women's protective health behavior. It is conducted on the rationale that it enables the healthcare providers to identify the women's population at risk of developing diseases associated with and related to menopause and choose the best prevention strategy which is acceptable and effective in the local setting.

\section{Methodology}

This retrospective cross-sectional descriptive study was conducted on 1000 women aged 40 - 60 years old. The study sample was calculated using Epi Info. 7 program. It totaled 1069 .

The participants were recruited randomly from the community Centres for women in Sana'a city. The inclusion criterion for subjects was according to WHO definition of natural menopause, the passage of 12 consecutive months of amenorrhea with no obvious pathological reason [1].

The absence of history of hysterectomy or surgical intervention to uterus or 
ovaries, intake of hormonal replacement therapy (HRT), chronic disease, uncontrolled medical condition, radiation therapy and drug abuse.

The purposes and significance of the study was explained to the women; they were given assurance for confidentiality of information then voluntary verbal consent was obtained from them.

Data was collected through structured interview using a pre-constructed questionnaire. The questionnaire was designed after an extensive review of literature and related studies. The validity of the questionnaire contents was assessed by a panel of experts in the field of study. The reliability of the questionnaire was determined through pilot study that was carried on (100) women attending the women's community centers in Sana'a city. Needed modifications were made. The questionnaire was designed to obtain data on socio-demographic characteristics such age, education, marital status, occupation and socioeconomic status, recorded from participant self-report. Social status was determined by ability to pay for basics. Low socio economic status had difficulty or was barely able to pay for immediate basics. Middle socio economic status was able to pay for basics and changes. High social class was able to pay for basics, changes, enjoy luxuries and accumulate wealth. The age of menopause of the participants, and the participants' mothers' age at menopause were recalled by the participants.

Physical characteristics such as body weight and height at menopause are based on self-report of the participant. Physiological characteristics are related to menopause such as age at menarche, regularity of menstruation, reproductive history such as parity, spontaneous abortion, as well as lifestyle characteristics such as physical activity (active women, reported being more active than other women of their age were more likely to be) and smoking. The questionnaire also included questions about experiencing related menopausal symptoms such as somatic, psychological, and genitourinary symptoms. The questionnaire included questions about women's protective health behaviors' information such as seeking medical consultation, regular physical exercise, and regular physical checkup.

Anthropometric measurements: the weight in kilograms and the height in centimeters at menopause were recorded. Then, the body mass index (BMI) was calculated using the formula body weight $/$ height $\left(\mathrm{kg} / \mathrm{m}^{2}\right)$. The term obesity was used for BMI values more than (28).

Data analysis; sixty-nine questionnaires were excluded from analysis for being incomplete or for the presence of medical history. Descriptive statistics was used to characterize the sample, such as, the mean age of menopause, standard deviation, menopausal symptoms, and protective health behaviors. The differences of age at menopause and its relationship to some socio demographics, biological and lifestyle factors were analyzed by using inferential statistics. P value was calculated, the significance criteria for the relationship was $\mathrm{P} \leq 0.05$.

\section{Results}

A sample of 1000 women whose data was used for analysis; their mean age was 50.6 years. Most of them were illiterate (86.6\%), married (62\%), non-working 
(66.3\%), and of low socioeconomic status (62\%), with a BMI $\leq 25$ (76.4\%), having sedentary activities (62.6\%) and non-smokers (61.5\%).

The mean age of menopause was $47.8 \pm 1.2$ years with a range of $40-55$ years. The corresponding mean age of menopause for participants' mothers was 47.66 \pm 303. The difference between daughters and mothers mean age at menopause was not statistically significant. Also mothers' and daughters' age at menopause clustered at 45 - 49 years of age interval. This may be indicative of familial tendency regarding age at menopause (Table 1 ).

Table 2 illustrated the relationship between certain socio-demographic factors and the mean age of menopause. It showed no significant effect of the three variables (education, occupation, and socioeconomic status) on the mean age of menopause $(\mathrm{P}>0.05)$. Regarding the relation between the mean age at menopause and education, literate women reported a later age at menopause compared to

Table 1. Relationship between participants' age at menopause mean S/D and participants' mothers' age at menopause mean S/D.

\begin{tabular}{cccc}
\hline Age & $\begin{array}{c}\text { F (frequency) } \\
(\mathrm{n}=1000)\end{array}$ & Mean S/D & $\begin{array}{c}\text { T } \\
\text { P. value }\end{array}$ \\
\hline Participants & & & \\
$40-44$ & 100 & $47.8 \pm 1.2$ & \\
$45-49$ & 750 & & \\
$50-55+$ & 150 & & \\
& & & \\
Mothers of participant & 44 & $0.077^{\star}$ \\
$40-44$ & 256 & & \\
$45-49$ & 66 & & \\
$50-55+$ & & & \\
\hline
\end{tabular}

${ }^{*} \mathrm{P} \leq 0.05$.

Table 2. Relationship between age at menopause mean S/D and socio-demographic characteristics.

\begin{tabular}{cccc}
\hline Factor & $\begin{array}{c}\text { F } \\
\text { No. (1000) }\end{array}$ & M.SD & $\begin{array}{c}\text { T } \\
\text { P value }\end{array}$ \\
Education & & & \\
Illiterate Literate, & 866 & $46.2 \pm 5.23$ & 1.45 \\
basic and above & 134 & $45.6 \pm 3.25$ & 0.055 \\
Occupation & & & \\
Non-working & 613 & $47.42 \pm 3.53$ & 1.6 \\
Working & 387 & $46.73 \pm 4.15$ & 0.073 \\
Socio-economic status & & & \\
Low & & & 1.1 \\
Middle & 629 & $47.51 \pm 3.64$ & 0.136 \\
\hline
\end{tabular}

${ }^{\star} \mathrm{P} \leq 0.05$. 
illiterate women. However, age at menopause in two groups did not vary significantly with women education. The reported mean age at menopause was 46.73 \pm 4.15 for non-working women. Working women reported age at menopause was $(47.42 \pm 3.53)$ later than the previous group. The age at menopause did not vary significantly among women according to their working status. The low socioeconomic status women reported a relatively lower age at menopause (47.51 $\pm 3.64)$ than women from the middle socioeconomic class $(47.81 \pm 4.79)$. The difference was not statically significant.

Table 3 indicated the relationship between some biological factors and age at menopause was statistically significant $(\mathrm{P}<0.05)$. These factors were, BMI, weight and height, age at menarche, parity, and spontaneous abortion. Age at menopause appears to decrease with respondent's higher rate of BMI. The relation between age and BMI was statistically significant. There is a trend toward late age at menopause in Taller women, the relationship was statically significant $(\mathrm{P}=0001)$. The age at menopause in women with body weight 55 kilogram or above was earlier than that in women with less than 55 kilogram. The difference

Table 3. Relationship between the age at menopause mean S/D and biological factors.

\begin{tabular}{|c|c|c|c|}
\hline Factor & $\begin{array}{c}F \\
\text { No. }(1000)\end{array}$ & M.SD & $\begin{array}{c}\text { T } \\
\text { P. value }\end{array}$ \\
\hline \multicolumn{4}{|c|}{ Body mass index (BMI) } \\
\hline$\leq 25$ & 748 & $47.59 \pm 3.84$ & $2.99^{*}$ \\
\hline$\geq 25$ & 252 & $46.79 \pm 3.46$ & 0.0001 \\
\hline \multicolumn{4}{|l|}{ Height } \\
\hline$\leq 155 \mathrm{~cm}$ & 796 & $47.40 \pm 3.37$ & $1.59^{*}$ \\
\hline$\geq 156 \mathrm{~cm}$ & 204 & $47.8 \pm 3.34$ & 0.056 \\
\hline \multicolumn{4}{|l|}{ Weight } \\
\hline Up to $54 \mathrm{~kg}$ & 746 & $47.66 \pm 3.84$ & $2.5^{*}$ \\
\hline$\geq 55 \mathrm{~kg}$ & 254 & $46.79 \pm 3.46$ & 0.006 \\
\hline \multicolumn{4}{|c|}{ Age at menarche } \\
\hline$\leq 16$ years & 854 & $47.70 \pm 2.18$ & $2.52^{*}$ \\
\hline$\geq 17$ years & 146 & $47.67 \pm 3.48$ & 0.005 \\
\hline \multicolumn{4}{|c|}{ Menstrual cycle } \\
\hline Regular & 888 & $47.35 \pm 4.31$ & $1.7^{*}$ \\
\hline Irregular & 112 & $46.67 \pm 3.44$ & 0.0478 \\
\hline \multicolumn{4}{|l|}{ Parity } \\
\hline $0-4$ & 82 & $47.25 \pm 4.55$ & $2.12^{*}$ \\
\hline$\geq 5$ & 918 & $48.31 \pm 4.15$ & 0.017 \\
\hline \multicolumn{4}{|c|}{ Spontaneous abortion } \\
\hline Negative & 795 & $47.8 \pm 3.44$ & $1.96^{*}$ \\
\hline Positive & 205 & $47.63 \pm 4.37$ & 0.025 \\
\hline
\end{tabular}

${ }^{*} \mathrm{P} \leq 0.05$. 
was statistically significant. Women who had their menarche at the age of 15 years or less had a statistically significant later age at menopause than those who had their at menarche at age of 16 years or above. The mean age at menopause for women of regular menstrual cycle was later compared to that in women of irregular menstrual cycle. The difference was statistically significant. A trend toward later menopause age with increasing parity was found, the mean age at menopause was later in women with 5 or more births than that of women with 4 or fewer births, the difference was statistically significant. The mean menopause for women of spontaneous abortion was earlier compared to that of women without spontaneous abortion. The difference was statically significant.

Table 4 showed the relationship between age at menopause and lifestyle factors. Women with sedentary activities had earlier age at menopause than active women. The difference was statistically significant (P. 0.22). Smoking Women had their menopause about half a year prior than non-smoking women. The difference is statistically significant (P. 0.42).

The occurrence of menopausal symptoms presented by the participants showed

Table 4. Relationship between age at menopause mean S/D and lifestyle factors.

\begin{tabular}{cccc}
\hline Factor & F & M.SD & T \\
Physical activity & No. (1000) & & \\
Sedentary Active & & & $0.2^{*}$ \\
Active & 626 & $47.92 \pm 3.64$ & 0.022 \\
Smoking & 374 & $48.4 \pm 3.84$ & \\
Not smokers & & & $1.97^{*}$ \\
Smokers & 615 & $47.81 \pm 4.15$ & 0.024 \\
\hline
\end{tabular}

${ }^{*} \mathrm{P} \leq 0.05$.

Table 5. Frequency of symptoms of menopause.

\begin{tabular}{ccc}
\hline Symptoms & F & $\%$ \\
\hline Somatic symptoms & No. (1000) & 100 \\
Hot flushes, sweating & & 100 \\
Sleep problem & 1000 & 37 \\
Heart discomfort & 1000 & 9.8 \\
Joint muscle problem & 340 & 74 \\
Psychological symptoms & 98 & 14.5 \\
Physical exertion & & 14.5 \\
Anxiety & 740 & 6.2 \\
Mental exertion & 145 & 5.5 \\
Irritability & 143 & 62 \\
Depression & 55 & 83.5 \\
Genitourinary problem & & 20 \\
Sexual problem & 835 & 805 \\
Dryness of the vagina & & \\
Bladder problem & & \\
\hline
\end{tabular}


that the most prevalent symptoms were hot flushes and sleep problems (100\%) followed by sexual problem and dryness of vagina $(83.5 \%, 82.5 \%)$ consecutively (Table 5). Physical exertion was reported by $74 \%$ of the total sample. The least reported symptoms were irritability and depression (6.2\%, 5.5\%) respectively.

The great majority of the women did not practice specific protective health behavior related to menopause (Table 6).

\section{Discussion}

Menopause is a normal developmental process it occurs around the 50th years of age. Life expectancy in developing world is estimated to be 65.15 years that imply that all women that live beyond the age of 50 would experience the event of menopause. As life expectancy increases, more women spend a large proportion of their lives in the menopausal state. It is projected that one in every two or three women would live for more than 30 years in menopausal state [22]. In developing world postmenopausal women proportion of the total population would be $14 \%$ by the year 2030 [2]. The menopausal event has been associated with risk of onset of several chronic diseases such as cardiovascular diseases, breast and endometrial cancer and osteoporosis [7] [8].

There are various biosocial factors which are believed to be associated with the age at menopause like socioeconomic status, body size, age at menarche regularity of menstrual cycle, parity, spontaneous abortion and lifestyle behaviors [23]-[31].

Menopausal transition symptoms occur to women in all the regions of the world. The prevalence of symptoms seeking help and demand for medical care differs widely with women of different region and cultural back area.

The present study was conducted on 1000 women in Sana'a city to estimate the natural age of menopause, identify factors associated with age, and estimate the prevalence of menopausal symptoms and women's related protective health behavior.

In the present study the mean age at natural menopause was 47.8 years which is comparable to those reported from some of the gulf, eastern Mediterranean and south-east Asia regions' countries, in Saudi Arabia 48.06 years [22], in the United Arab Emirates 47.3 years [32], in Iraq 47.96 years [33], in Iran 47.9 years,

Table 6. Menopause women protective health behavior

\begin{tabular}{ccc}
\hline Behaviors & F & $\%$ \\
\hline Physical checkup & No. (1000) & \\
\hline Breast, cervical exam, pap test and mammography & 52 & 5.2 \\
Regular physical exercise & 45 & 4.5 \\
Intake of calcium & 25 & 2.5 \\
Intake of vitamin D & 25 & 2.5 \\
Seeking medical consultation & 24 & 2.4 \\
\hline
\end{tabular}


in Egypt 47.44 years [34], in Turkey 47.8 years [35], in India 47.1 years [36], in Malaysia 47.96 years [37]. The mean age at natural menopause in the current study is lower than those reported in western countries [3]. The variation may be attributed to bio-cultural factors.

Familial tendency toward the age of menopause may prove the role of genetic factor in determining the age of menopause; the mean age of menopause in the mothers of the participants showed no significant difference from that of the participants. This result supports previous studies that reported significant positive relationship between menopausal age in mothers and that of the participants [23] [36] [37].

With respect to biological factors, the mean menopausal age was later in women with higher BMI value the results are consistent with other studies reports [19] [24] [25] [35] [38]. Similar studies reported no influence [21] [27] [29] [30].

In this study, the BMI value was calculated from present anthropometric measurement and self-report by the participant about any change in the measurement from that at the age of menopause. Therefore, a prospective future study is recommended.

The mean menopausal age was later in taller women that agree with some prior studies' reports [25] [28], while other researchers found no difference in age at menopause according to anthropometric measurement [39] [40].

The current study indicated statistically significant inverse relationship between age at menopause and age at menarche, early menarche late menopause and vice versa, the results are similar to other studies [23] [31] [38]. Conversely, some findings showed no statistically significant association. Also some studies reported early age at menopause and early age at menarche or late age at menopause and late age at menarche [38].

This study revealed that age at menopause for women with regular menstrual cycle was later compared to women with irregular menstrual cycle the difference was not statistically significant the results are congruent with earlier results [38]. However, another study reported that age at menopause was not significantly associated with regularity of menstrual cycle [41].

In the present study, high parity was significantly associated with later age at menopause. The results are in accordance with previous studies' reports [27] [29], while other studies did not confirm this association [20].

In our study women with the positive history of spontaneous abortion reported earlier age at menopause than those with negative history. The difference was statistically significant. Results are consistent with other findings that spontaneous abortion had influence on menopausal age [20]. Differently, it was not observed in another study [21].

Investigating the relationship between menopausal age and lifestyle behaviors such as physical activity and smoking, the results of this study agree with earlier reported studies [26] [42] that found increased physical activity was associated 
with earlier age at menopause [42]. However, in other studies, the association between physical activity and age at menopause was inconclusive [38] [43] [44]. A consistent finding has been a positive association between smoking and earlier age at menopause [31] [38] [45]. The results of the present study conform with the previous findings. Conversely, some other studies reported no significant relation [21] [46].

Regarding the influence of socio-demographic factors such as education, occupation, and socioeconomic status on age at menopause the present study revealed no association between the three variables and the age at menopause. The result agrees with the results of the previous studies [10] [33]. Regarding the socioeconomic status, some studies found significant association between socioeconomic status and age at menopause [21] [46]. Other studies reported an association between education and age at menopause more education. Regarding to later age of menopause [20], other researcher reported higher education to be associated with lower age at menopause [38]. Other researcher reported occupation as a determinant of age at menopause [20].

All women experience menopausal symptoms. Women may have all the symptoms or may have just a few. The intensity of menopausal symptom can range from mild to quite severe. According to WHO [1], a variety of symptoms occurring either singly or together are frequently reported as being a part of menopausal symptoms. These include physical and psychological problems. However, it is now recognized that most of these symptoms are not specific to the menopause. Many are related to aging process or occur because of stresses in mid-life years. Hot flushes and night sweat are the symptoms most consistently associated with menopause. The present study revealed some menopausal symptoms prevalence to be higher than that reported in other countries; all the participants $100 \%$ experienced hot flushes compared to $90.7 \%$ in Egypt [47] in Libya [48] 32\% in Pakistani women [49] 45\% in North American women [3] and the United Arab Emirates women [32] 73.90\% in Dutch women and 50\% in Turkish women [37]. Another dominant menopausal symptom was sleep problem similar rating was reported in Egypt [47], Pakistan [49], United Kingdom India [3] but with an increased frequency in our results $100 \%$. The frequency of sexual problems observed in the study $83.5 \%$ was almost similar to that reported in Egypt [47] 89.1\%. The psychological problem was the least frequently reported symptom in contrast to that is south-east Asia, Europe \& North America. The possible explanation for this may be that women consider the menopausal event as a transition period, which all women go through. Another explanation may be the social support the older women get as they are highly regarded culturally and religiously.

Though each woman suffered more than one menopausal symptom the great majority, did not practice protective health behaviors, seek medical consultation, perform physical exercise or had the periodical physical examination. Other researchers reported similar observations [49] [50] [51] [52]. A possible explana- 
tion for this may be that women view menopause as the normal aging process, so they did not focus much on the symptoms. Another possible explanation may be lack of perceived awareness of susceptibility to disease. Women may have gained knowledge and experience to cope effectively with such biological changes is also a potential explanation.

The results indicate a need for emphasizing the importance of protective health behavior, particularly regular physical exercise as women at later years of life are less active as they are relieved of bothers of taking care of family and meeting the needs of the growing children.

\section{Conclusion}

The mean age of menopause recorded in this study was $47.8 \pm 1.2$ years. Age at menopause is significantly influenced by biological factor and lifestyle behaviors. The prevalence of menopausal symptoms was quite high. Menopause is an important emerging issue due to increased longevity and consequent growing population. Health education efforts are made to increase women' knowledge about menopause and enable them to promote their quality of life. Similar cross national studies are conducted. Prospective longitudinal research is needed to study the phenomena in more depth.

\section{Limitations}

As far as our knowledge this is the first study of its kind in Yemen. The study was broad in nature and explored many different variables to point an overall picture of menopause among Yemeni women. This study found several positive statically significant correlations that may provide some insight in the topic and could be a focus of future research, to study each variable in its entity. The limitation of this study is discussed below.

One limitation is the participants of the study were women attending community centers only in Sana'a who may possess traits that differ from that of women in other parts of Yemen, so the result may not be generalizable.

Another limitation is the study findings based on women's recall of their age at menopause that may be subject to recall bias.

The participants in this study did not undergo focused diagnostic evaluation for their symptoms to confirm the specific etiology of their symptoms, which is also a potential limitation.

\section{References}

[1] WHO (1996) Research on the Menopause. WHO Technical Report Series, World Health Organization, Geneva.

[2] Population Reference Bureau (2014) World Population Data Sheet. http://www.prb.org/pdf14/2014-world-populationdata-sheet

[3] Palacios, S., Henderson, V., Siseles, N. and Tan, D. (2010) Age of Menopause and Impact of Climacteric Symptoms by Geographical Region. Climacteric, 13, 419-428. https://doi.org/10.3109/13697137.2010.507886 
[4] Fallahzadah, H. (2010) Quality of Life after the Menopause in Iran: A Population Study. Quality of Life Research, 19, 813-819. https://doi.org/10.1007/s11136-010-9644-2

[5] Thurston, R. and Johnson, B. (2017) Menopausal Symptoms and Cardiovascular Disease Mortality in the Women's Ischemia Syndrome Evaluation (WISE). Menopause, 24, 126-132. https://doi.org/10.1097/GME.0000000000000731

[6] Hunter, M.M., Nakagawa, S. and Van Den Eeden, S.K. (2016) The Impact of Vaginal Symptoms in Postmenopausal Women. Menopause, 23, 46-60. https://doi.org/10.1097/GME.0000000000000482

[7] Hillard, T. (2010) The Postmenopause Bladder. Menopause International, 16, 74-80.

[8] Thomas, H.N. and Thurston, R.C. (2016) A Biopsychosocial Approach to Women's Sexual Function and Dysfunction at Midlife: A Narrative. Maturitas, 87, 49-60.

[9] Joyce, T., Broom Berger, T. and Howard, M. (2011) Mood and Menopause: Findings from the Findings from the Women's Health across the Nation (SWAN) over 10 Years. Obstetrics \& Gynecology Clinics of North America, 38, 609-625.

[10] Pathak, R.K. and Parashar, P. (2010) Age at Menopause and Associated Bio-Social Factors of Health in Punjab of Women. The Open Anthropology Journal, 3, 172-180.

[11] Thulkar, J. and Singh, S. (2015) Overview of Research Studies on Osteoporosis in Menopausal Women since the Last Decade. Journal of Midlife Health, 6, 104-107.

[12] Gold, E.B. (2011) The Timing of the Age at Which Natural Menopause Occurs. $O b$ stetrics and Gynecology Clinics of North America, 30, 425-440. https://doi.org/10.1016/j.ogc.2011.05.002

[13] Gong, D., San, J., Zhou, Y. and Zou, C. (2016) Early Age at Natural Menopause and Risk of Cardiovascular and All-Cause Mortality: A Meta-Analysis of Prospective Observational Studies. International Journal of Cardiology, 20, 5-119. https://doi.org/10.1016/j.ijcard.2015.10.092

[14] Tulkary and Singhs (2015) Overview of Research Studies on Osteoporosis in Menopausal Women since the Last Decade. Mid-Life Health, 6, 104-107. https://doi.org/10.4103/0976-7800.165589

[15] Van Wayenburg, C., Van der Schauw, Y., Van Noord, P., et al. (2000) Age at Menopause, Body Mass Index and the Risk of Colorectal Cancer Mortality in the Dutch Diagnostisstich ondezoek Mammacorcinoom (DOM). Cohort Epidemiology, 11, 304-308. https://doi.org/10.1097/00001648-200005000-00013

[16] Jim, R.S., Aimee, K.J. and Gary, E. (2014) Memory Decline in Peri- and Post-Menopausal Women: The Potential of Mind-Body Medicine to Improve Cognitive Performance. Integrative Medicine Insights, 3, 17-23.

[17] Xu, W.H., et al. (2004) Menstrual and Reproductive Factors and Endometrial Cancer Risk: Results from a Population-Based Case-Control Study in Urban Shanghai. International Journal of Cancer, 4, 613-619.

[18] Wellons, M.F., Juliana, J.M. and Catherine, K. (2017) Ovarian Aging in Women with Diabetes: An Overview. The European Menopause Journal, 96, 109-113. https://doi.org/10.1016/j.maturitas.2016.11.019

[19] Collaborative Group on Hormonal Factors in Breast (2012) Menarche, Menopause, and Breast Cancer Risk: Individual Participant Meta-Analysis, Including 118964 Women with Breast Cancer from 117 Epidemiological Studies. The Lancet Oncology, 13, 1141-1151.

[20] Ahuja, M. (2016) Age of Menopause and Determinants of Menopause Age: A PAN 
India Survey by IMS. Journal of Mid-Life Health, 7, 126-131. https://doi.org/10.4103/0976-7800.191012

[21] Abdollahi, A., et al. (2013) The Menopausal Age and Associated Factors in Gorgan, Iran. Medical Journal of the Islamic Republic of Iran, 419-428.

[22] Alquaize, A., Tayel, S.H. and Hibaba, F. (2013) Assessment of Symptoms of Menopause and Their Severity among Saudi Women in Riyadh. Annals of Saudi Medicine, 1, 63-67. https://doi.org/10.5144/0256-4947.2013.63

[23] Canavez, F.S., Werneck, G.L., Parente, R.C., Celeste, R.K. and Faerstein, E. (2011) The Association between Educational Level and Age at the Menopause: A Systematic Review. Archives of Gynecology and Obstetrics, 283, 83-90. https://doi.org/10.1007/s00404-009-1323-6

[24] Stein, A.Z., Barid, D. and Kesner, S. (2008) Mother Menopause Age Is Associated with Her Daughter Early Follicular Phase Urinary Follicle Stimulating Hormone Level. Menopause, 15, 940-944. https://doi.org/10.1097/gme.0b013e31816429e5

[25] Aydın, Z.D., Erbaş, B., Karakuş, N., Aydın, O. and Ozkan, Ş.K. (2005) Sun Exposure and Age at Natural Menopause: A Cross-Sectional Study in Turkish Women. Maturitas, 52, 235-248. https://doi.org/10.1016/j.maturitas.2005.02.023

[26] Gold, E.B., Crawford, S.L., Avis, N.E., Crandall, C.J., Matthews, K.A., Waetjen, L.E., et al. (2013) Factors Related to Age at Natural Menopause: Longitudinal Analyses from SWAN. American Journal of Epidemiology, 178, 70-83. https://doi.org/10.1093/aje/kws421

[27] Perez-Alcala, I., Sievert, L.L., Obermeyer, C.M. and Reher, D.S. (2013) Cross-Cultural Analysis of Factors Associated with Age at Natural Menopause among Latin-American Immigrants to Madrid and Their Spanish Neighbors. American Journal of Human Biology, 25, 780-788. https://doi.org/10.1002/ajhb.22447

[28] Bjelland, E.K., Wilkosz, P., Tanbo, T.G. and Eskild, A. (2014) Is Unilateral Oophorectomy Associated with Age at Menopause? A Population Study (the HUNT2 Survey). Human Reproduction, 29, 835-841. https://doi.org/10.1093/humrep/deu026

[29] Li, L., Wu, J., Pu, D., Zhao, Y., Wan, C., Sun, L., et al. (2012) Factors Associated with the Age of Natural Menopause and Menopausal Symptoms in Chinese Women. Maturitas, 73, 354-360. https://doi.org/10.1016/j.maturitas.2012.09.008

[30] Hayatbakhsh, M.R., Clavarino, A., Williams, G.M., Sina, M. and Najman, J.M. (2012) Cigarette Smoking and Age of Menopause: A Large Prospective Study. Maturitas, 72, 346-352. https://doi.org/10.1016/j.maturitas.2012.05.004

[31] Sapre, S. and Thakur, R. (2014) Lifestyle and Dietary Factors Determine the Age at Natural Menopause. Journal of Mid-Life Health, 5, 3-5. https://doi.org/10.4103/0976-7800.127779

[32] Risks, D., Benner, A., Ezimokhai, M. and Micall, R. (1998) The Age and Symptomatology of Natural Menopause among United Arab Emirates Women. Maturation, 9, 197-202.

[33] Dhia Al-Deen, L. and Sadik, F. (2009) Age at Natural Menopause and Factors Influencing Its Timing in a Sample of Iraqi Women in Baghdad. Iraqi Journal of Community Medicine, 1, 1-8.

[34] Sallam, H., Galal, A. and Rasheed, A. (2006) Menopause in Egypt Past and Present Perspective. Climatic, 9, 421-429. https://doi.org/10.1080/13697130601030170

[35] Demure, O. and Col, M. (2004) The Age of Menopause and Associated Factor at Health Center Area in Ankara, Turkey. Maturation, 49, 211-219.

[36] Sidhu, S., Kaur, A. and Sidhu, M. (2005) Age at Menopause in Educated Women of Amritsar (Punjab). Journal of Human Ecology, 18, 49-51.

https://doi.org/10.1080/09709274.2005.11905806 
[37] Sahan fan, Sh., Abdulrahim, B.A., Shah, Rez., et al. (2006) Age of Menopause and Menopausal Symptoms among Malaysian Women Who Referred to Health Clinic in Malaysia. Shiraz E Medical Journal, 7, 1-9.

[38] Parazzini, F. and Progetto Menopause Italia Study Group (2007) Determinants of Age at Menopause in Women Attending Menopause Clinics in Italy. Maturitas, 56, 280-287. https://doi.org/10.1016/j.maturitas.2006.09.003

[39] Hardy, B. (2008) Body Mass Index Trajectories and Age at Menopausal in a British Cohort. Maturation, 59, 314.

[40] Toa, X., Jiang, A., Yin, L., et al. (2015) B.M.I. and Menopausal Meta-Analysis. Menopause, No. 4, 496-497.

[41] Priya, B., Anurage, Ch, Son, K., et al. (2014) The Epidemiological Determinant of Age at Natural Menopause in Rural Women of Punjab. Journal of Research in Medical and Dental Science, 2, 24-28.

[42] Gudmundsdottir, S.L., Flanders, W.D. and Augestad, L.B. (2013) Physical Activity and Age at Menopause: The Nord-Trondelag Population-Based Health Study. Climacteric, 16, 78-87. https://doi.org/10.3109/13697137.2011.646344

[43] Zsakia, A., Mascie, N. and Bodzer, N. (2015) The Relationship between Some Indicators of Reproductive History, Body Fatness and Menopausal Transition in Hungarian Women. Journal of Physiological Anthropology, 22, 34-35.

[44] Romita, P., Sing, D., Deben, S., et al. (2016) Age at Menopause and Its Determinants. Annals of International Medical and Dental Research, 2, 610-614.

[45] Butts, S.F., Sammel, M.D., Greer, C., Rebbeck, T.R., Boorman, D.W. and Freeman, E.W. (2014) Cigarettes, Genetic Background and Menopausal Timing: The Presence of Single Nucleotide Polymorphisms in Cytochrome P450 Genes Are Associated with Increased Risk of Natural Menopause in European-American Smokers. $\mathrm{Me}$ nopause, 21, 694-701. https://doi.org/10.1097/GME.0000000000000140

[46] Beila, U. (2002) Determinants of Age at Menopause Orzegl lek, 9, 165-169.

[47] Abedzadeh-kalahroud, M., Taebi, M. and Sadat, Z. (2012) Prevalence and Severity of Menopause Symptoms and Related Factors among Women 40-60 Years in Kashan Iran. Nursing and Midwifery Studies, 1, 88-93. https://doi.org/10.5812/nms.8358

[48] Rostami, A., et al. (2004) The Effect of Health Education Program on Quality of Women's Life in Menopause. Daneshvar Medicine, 11, 19-24.

[49] Lutfi, I., Abdel Aziz, F., Dabbous, N.I. and Dabous, H.M. (2006) Women Perception and Experience of Menopause. A Community-Based Study in Alexandria, Egypt. Eastern Mediterranean Health Journal, 12, S93-S106.

[50] Taher, Y., Ben Emhemed, H.W. and Twaiti, A.M. (2012) Menopausal Age-Related Factors and Climacteric Symptoms in Libyan Women. Climacteric, 16, 179-184. https://doi.org/10.3109/13697137.2012.682107

[51] Zultak, J.M. and Skk, B. (2014) Health Behavior of Postmenopausal Women. Menopause Review, 13, 226.

[52] Mustafa, E. and Sabri, J.M. (2012) Perception and Experience Regarding Menopause among Menopause Attending Teaching Hospital in Erbil. Global Health Science, 4, 170-178. 